\title{
Asymmetry of the Indian Ocean Dipole. Part I: Observational Analysis*
}

\author{
CHI-Cherng Hong \\ Department of Science, Taiwan Municipal University of Education, Taipai, Taiwan \\ TIM LI \\ IPRC/SOEST, University of Hawaii at Manoa, Honolulu, Hawaii \\ LiNHo \\ Department of Atmospheric Sciences, National Taiwan University, Taipai, Taiwan \\ JONG-SEONG KUG \\ Climate Environment System Research Center, Seoul National University, Seoul, South Korea
}

(Manuscript received 6 September 2007, in final form 13 January 2008)

\begin{abstract}
The physical mechanism for the amplitude asymmetry of SST anomalies (SSTA) between the positive and negative phases of the Indian Ocean dipole (IOD) is investigated, using Simple Ocean Data Assimilation (SODA) and NCAR-NCEP data. It is found that a strong negative skewness appears in the IOD east pole (IODE) in the mature phase [September-November (SON)], while the skewness in the IOD west pole is insignificant. Thus, the IOD asymmetry is primarily caused by the negative skewness in IODE.

A mixed-layer heat budget analysis indicates that the following two air-sea feedback processes are responsible for the negative skewness. The first is attributed to the asymmetry of the wind stress-ocean advection-SST feedback. During the IOD developing stage [June-September (JJAS)], the ocean linear advection tends to enhance the mixed-layer temperature tendency, while nonlinear advection tends to cool the ocean in both the positive and negative events, thus contributing to the negative skewness in IODE. The second process is attributed to the asymmetry of the SST-cloud-radiation (SCR) feedback. For a positive IODE, the negative SCR feedback continues with the increase of warm SSTA. For a negative IODE, the same negative SCR feedback works when the amplitude of SSTA is small. After reaching a critical value, the cold SSTA may completely suppress the mean convection and lead to cloud free conditions; a further drop of the cold SSTA does not lead to additional thermal damping so that the cold SSTA may grow faster. A wind-evaporation-SST feedback may further amplify the asymmetry induced by the aforementioned nonlinear advection and SCR feedback processes.
\end{abstract}

\section{Introduction}

The Indian Ocean dipole (IOD) is a zonal mode of the interannual variability of the Indian Ocean SST (Saji et al. 1999; Webster et al. 1999). It appears as an

* SOEST Contribution Number 7246 and IPRC Contribution Number 499.

Corresponding author address: Dr. Chi-Cherng Hong, Department of Science, TMUE, 1 Ai Kuo West Road, Taipei 10001, Taiwan.

E-mail: cchong@tmue.edu.tw east-west-oriented dipole of SST anomalies (SSTA) in the Indian Ocean. A positive IOD event is defined as above-normal SSTA in the tropical western Indian Ocean and below-normal SSTA in the tropical eastern Indian Ocean (Saji et al. 1999). It has been argued that the east and west parts of the dipole might not be physically coherent (Dommenget and Latif 2002), although there are evidences showing that IOD is an air-sea coupling mode and can develop with or without the presence of ENSO (Li et al. 2002, 2003; Baquero-Bernal et al. 2002; Saji and Yamagata 2003; Lau and Nath 2004; Yu and Lau 2004; Zhong et al. 2005; Behera et al. 2006).

Based on the previous observational (Saji et al. 1999; Webster et al. 1999; Saji and Yamagata 2003; Krishna- 


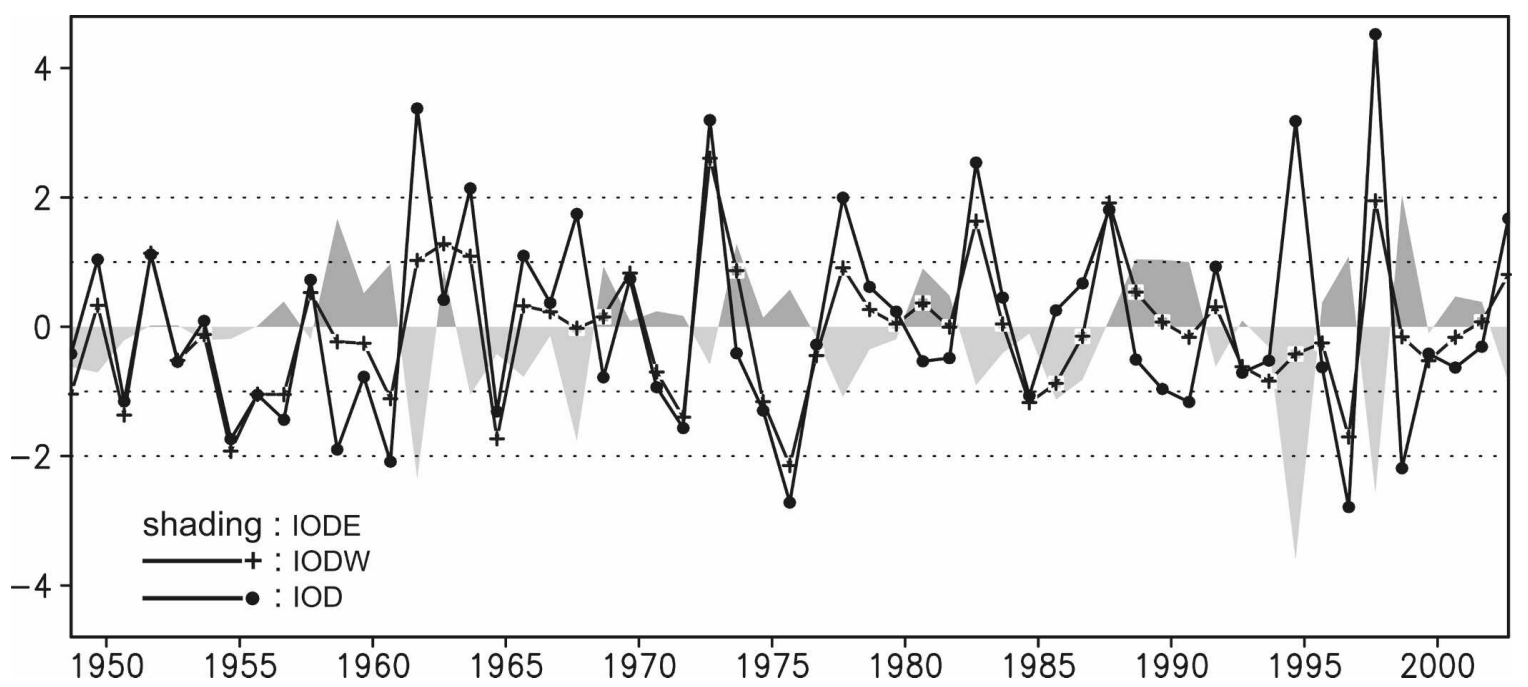

FIG. 1. Time evolution of normalized SSTA (NOAA SST) in the IODE (shaded), IODW (line with cross), and the IOD index (line with circle). The standard deviations for each index are $\sigma_{\mathrm{IODE}}=0.34^{\circ} \mathrm{C}, \sigma_{\mathrm{IODW}}=0.25^{\circ} \mathrm{C}$.

murthy and Kirtman 2003), modeling (Li et al. 2002; Shinoda et al. 2004; Lau and Nath 2004; Zhong et al. 2005; Cai et al. 2005; Behera et al. 2006), and theoretical (Li et al. 2003; Zhong et al. 2005) studies, one may conclude that IOD is a seasonally dependent mode whose phase is locked into the annual cycle and the Asian monsoon; as a consequence of this seasonal dependence, IOD grows rapidly in northern summer, reaches a mature phase in northern fall, and decays and transforms into a basin SST mode in subsequent northern winter and spring.

As the IOD index is defined by the SSTA difference between the west pole and the east pole, the index itself may not fully reflect the variability in the Indian Ocean (Huang and Kinter 2001). Observations show that the SST variance in the east pole is larger than that of the west pole in the peak phase of IOD (Saji and Yamagata 2003, their Fig. 5; Hong et al. 2008a). This suggests that the contribution of both the poles to the IOD index might be different.

Figure 1 shows the time evolution of the SSTA in the east and west poles during the IOD peak season, September-November (SON). Note that the SSTA amplitude in the west pole is nearly symmetric between the positive and negative phases, but it becomes significantly asymmetric in the east pole. If one focuses on the extreme years (when the normalized SSTA amplitudes are greater than 1 , i.e., $|\sigma| \geq 1$ ), there is an obvious asymmetry between positive and negative events in the east pole. For example, for the negative SSTA events in the east pole such as those in 1961, 1994, and 1997, the SSTA amplitudes are stronger than $-2 \sigma$, but the largest positive SSTA amplitudes in the east pole hardly reach to $2 \sigma$.
The objective of the present study is to reveal the physical mechanism responsible for the IOD amplitude asymmetry in the east pole. Many previous studies are based on the positive minus negative IOD composites, which could not address this asymmetry issue. This study is partially motivated by long-term air-sea coupled simulations by the Scale Interaction Experiment-Frontier Research Center for Global Change (SINTAX-F1) model (Luo et al. 2003), which successfully simulates both the ENSO and IOD (Tozuka et al. 2005; Behera et al. 2006). Here we investigate specific dynamic and thermodynamic processes that give rise to the IOD amplitude asymmetry, by analyzing both observational data and SINTEX-F1 model outputs. In Part I, we present the results from the observational [including Simple Ocean Data Assimilation (SODA) mixed-layer heat budget] analysis. The diagnosis of the model simulations will be presented in Hong et al. (2008b, hereafter Part II).

This paper is organized as follows: In section 2, we describe the data to be used. In section 3, we define the skewness to measure the amplitude asymmetry in the east and west poles. A mixing-layer heat budget analysis is put forth in section 4 to find out the specific dynamic and thermodynamic processes that give rise to the asymmetry of SSTA tendencies between the positive and negative phases. Finally, concluding remarks and a discussion are given in the last section.

\section{Data}

The SODA product of Carton et al. (2000) for 19502001 is used as a major dataset for the ocean diagnosis. 
The data resolution is $1^{\circ}$ in the zonal, and variable (from $0.45^{\circ}$ at the equator to $1^{\circ}$ at high latitude) in the meridional direction. There are 20 levels in the vertical, with a variable grid spacing of $15 \mathrm{~m}$ at the surface and $737 \mathrm{~m}$ at the bottom. The SODA data have been previously used for studying the Indian and Pacific Ocean dynamics (e.g., Xie et al. 2002; An and Jin 2004; Kug et al. 2005). In addition, the National Centers for Environmental Prediction-National Center for Atmospheric Research (NCEP-NCAR) reanalysis (Kalnay et al. 1996) and National Oceanic and Atmospheric Administration (NOAA) reconstructed sea surface temperature (Smith et al. 1996) data are used for diagnosing the surface heat fluxes and the asymmetry of SSTA.

In the present study, the monthly mean climatology is first calculated for the period of 1950-2001 and anomalies are then defined as departures from this climatology. A procedure is applied to the NOAA SST to remove a linear warming trend in the Indian Ocean [Saji and Yamagata $2003, \sim 0.5^{\circ} \mathrm{C}(100 \mathrm{yr})^{-1}$ ]. A 3 -month running mean is then applied to all datasets to filter out the intraseasonal variation. Here, the east pole $\left(10^{\circ} \mathrm{S}-0^{\circ}, 90^{\circ}-110^{\circ} \mathrm{E}\right.$, hereafter IODE) and west pole $\left(10^{\circ}-10^{\circ} \mathrm{N}, 50^{\circ}-70^{\circ} \mathrm{E}\right.$, hereafter IODW) boxes are same as Saji et al. (1999). The following two conditions are applied when we select IOD composite cases: 1) the difference of normalized SSTA between IODW and IODE is larger than one standard deviation $(\sigma)$, and 2$)$ zonal wind anomaly averaged over the central Indian Ocean $\left(5^{\circ} \mathrm{S}-5^{\circ} \mathrm{N}, 70^{\circ}-90^{\circ} \mathrm{E}\right)$ is easterly (westerly) for the positive (negative) IOD event. The ENSO event is defined when the normalized Niño-3 index in November-January (NDJ) is larger than $1 \sigma$. The so-defined ENSO events are similar to Trenberth (1997).

\section{Measuring the IOD asymmetry}

The skewness is a measure of the asymmetry of a probability distribution function, and a value of 0 represents a normal distribution (White 1980). Here we adopt the skewness to measure the amplitude asymmetry of IOD, following An and Jin (2004). The skewness is defined as

$$
\text { Skewness }=m_{3} /\left(m_{3}\right)^{3 / 2},
$$

where $m_{k}$ is the $k$ th moment,

$$
m_{k}=\sum_{i=1}^{N} \frac{\left(x_{i}-\bar{X}\right)^{k}}{N}
$$

and $x_{i}$ is the $i$ th observation (seasonal mean), $\bar{X}$ the climatological mean, and $N(=52)$ the number of observations. The statistical significance of the skewness may be estimated if the number of independent samples is known (White 1980). Because the time series of SSTA is not statistically independent, we use a range estimate instead. It is estimated that a confidence level of $95 \%$ corresponds to the amplitude of the skewness exceeding \pm 0.67 .

The distribution of the SSTA skewness in the Indian Ocean (Fig. 2) shows that there is a significant negative skewness off the coast of Sumatra, and that the skewness is insignificant over the western Indian Ocean. A further examination shows that the negative skewness in IODE is season dependent; that is, the negative skewness in the east pole can only be identified in the mature phase of IOD (SON) and becomes a little skewed during the IOD developing phase [JuneAugust (JJA)] (see Table 1).

An interesting question is whether or not the negative skewness in the east pole is attributed to remote ENSO forcing, as the amplitude of El Niño is in general greater than that of La Niña. To answer this question, we remove all the ENSO events (El Niño events: 1951, 1957, 1963, 1965, 1969, 1972, 1976, 1982, 1987, 1991, 1997; La Niña events: 1950, 1954, 1955, 1964, 1970, $1971,1973,1975,1988,1998,1999)$ and recalculate the skewness. It turns out that the skewness of IODE just drops a little bit (from -1 to -0.97 ) and still passes the statistical $t$ test at $95 \%$ confidence level. [In this case the threshold is a little higher because of the decreasing sample number $(N=30)$.] The results above indicate that the negative skewness in IODE is primarily attributed to local air-sea feedback processes in the Indian Ocean.

Because the surface wind, SST, and thermocline depth anomalies are dynamically linked, we also examine the skewness for other variables such as the depth of the $20^{\circ} \mathrm{C}$ isotherm (hereafter referred to as D20) in the east pole and the zonal wind stress anomaly $\left(\tau_{x}\right)$ in the central equatorial Indian Ocean $\left(5^{\circ} \mathrm{S}-5^{\circ} \mathrm{N}, 70^{\circ}-\right.$ $\left.90^{\circ} \mathrm{E}\right)$. Table 2 lists the values of the skewness for D20 and $\tau_{x}$, both of which have significant negative skewness. This points out that the SSTA amplitude asymmetry may arise primarily from local dynamic air-sea feedback processes. In the next section, through a detailed mixed-layer heat budget analysis, we reveal the specific processes that give rise to the asymmetry.

\section{Cause of the IOD asymmetry}

To understand the relative roles of ocean advection and surface heat fluxes in causing the SSTA amplitude asymmetry in IODE, we analyze the oceanic mixedlayer heat budget and make composites for the positive and negative SSTA events. The mixed-layer tempera- 

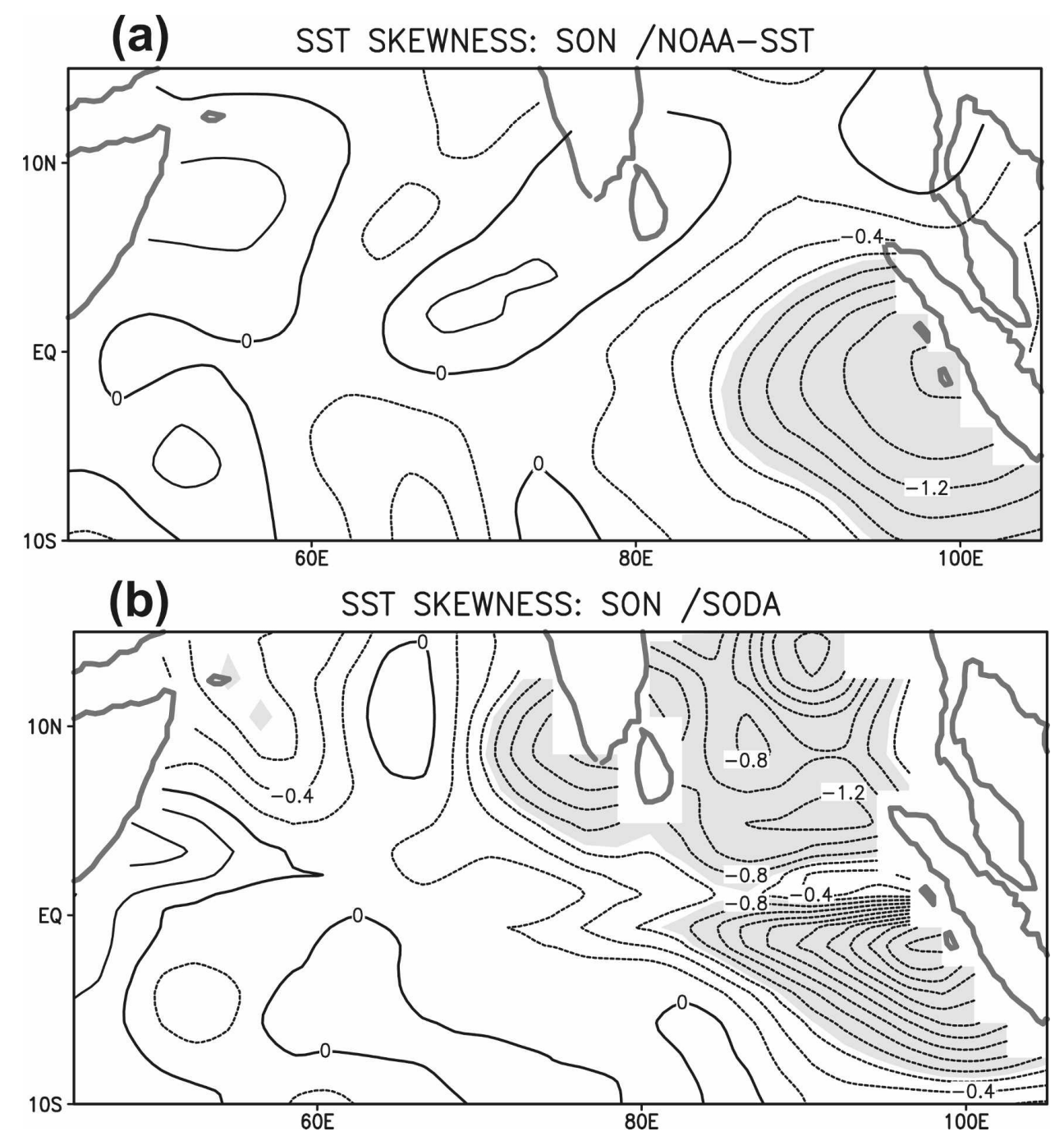

FIG. 2. Distribution of the skewness of the Indian Ocean SSTA in SON for the (a) NOAA and (b) SODA datasets. The calculation is based on the data for 1950-2001. Shading indicates SSTA skewness greater than $95 \%$ confidence level.

ture tendency equation may be written as ( $\mathrm{Li}$ et al. 2002)

$$
\begin{aligned}
\frac{\partial T^{\prime}}{\partial t}= & -\left(\mathbf{V}^{\prime} \cdot \boldsymbol{\nabla} \bar{T}+\overline{\mathbf{V}} \cdot \boldsymbol{\nabla} T^{\prime}\right)-\left(\mathbf{V}^{\prime} \cdot \boldsymbol{\nabla} T^{\prime}\right) \\
& +\frac{1}{\rho C_{P} H}\left(Q_{\mathrm{SW}}+Q_{\mathrm{LW}}+Q_{\mathrm{LH}}+Q_{\mathrm{SH}}\right)^{\prime}+R,
\end{aligned}
$$

where $T$ denotes the mixed-layer temperature; $\mathbf{V}=(u$, $v, w)$ is three-dimensional ocean current, which is de-

TABLE 1. The skewness of the IODE and IODW in JJA and SON.

\begin{tabular}{ccc}
\hline \hline Location/season & JJA & SON \\
\hline IODE & 0.1 & -1.0 \\
IODW & 0.1 & 0.1 \\
\hline
\end{tabular}

fined as the vertical average from surface to the bottom of mixed layer; $\boldsymbol{\nabla}=(\partial / \partial x, \partial / \partial y, \partial / \partial z)$ denotes threedimensional (3D) gradient operator; ( )' represents the anomaly variables; $\left(^{-}\right)$represents the climatological mean variables; term $-\left(\mathbf{V}^{\prime} \cdot \boldsymbol{\nabla} \bar{T}+\bar{V} \cdot \boldsymbol{\nabla} T^{\prime}\right)$ is the summation of linear advection terms; term $-\left(\mathbf{V}^{\prime} \cdot \nabla T^{\prime}\right)$ denotes 3D nonlinear temperature advection term; $Q_{\mathrm{sw}}$, $Q_{\mathrm{LW}}, Q_{\mathrm{LH}}$, and $Q_{\mathrm{SH}}$ represent the net downward shortwave radiation at the ocean surface, net downward sur-

TABLE 2. The skewness of the SODA SST, D20, and $\tau_{x}$ (zonal wind stress) anomalies in SON [SST and D20 are over the east pole $\left(10^{\circ} \mathrm{S}-0^{\circ}, 90^{\circ}-110^{\circ} \mathrm{E}\right)$ and $\tau_{x}$ is over the central equatorial Indian Ocean $\left.\left(5^{\circ} \mathrm{S}-5^{\circ} \mathrm{N}, 70^{\circ}-90^{\circ} \mathrm{E}\right)\right]$.

\begin{tabular}{cccc}
\hline \hline & SSTA & D20 & $\tau_{x}$ \\
\hline Skewness & -1.2 & -0.8 & -0.8 \\
\hline
\end{tabular}


TABLE 3. Years of positive and negative IODE events for composite.

\begin{tabular}{llc}
\hline \multicolumn{1}{c}{ Catalog } & & Number \\
\hline $\begin{array}{l}\text { Positive IODE } \\
\text { (Negative IOD) }\end{array}$ & $1954,1956,1958,1959,1960,1964$ & 11 \\
$\begin{array}{l}\text { Negative IODE } \\
\text { (Positive IOD) }\end{array}$ & $1961,1963,1992,1996,1998$ & \\
\hline
\end{tabular}

face longwave radiation, and surface latent and sensible heat fluxes; $R$ represents the residual term; $\rho\left(=10^{3} \mathrm{~kg}\right.$ $\left.\mathrm{m}^{-3}\right)$ is the density of water; $C_{P}\left(=4000 \mathrm{~J} \mathrm{~kg} \mathrm{~K}^{-1}\right)$ is the specific heat of water; and $H$ denotes the mixing-layer depth. Here, a positive heat flux indicates heating the ocean. As the SODA data do not show the significant change in the mixed-layer depth between the positive and negative IODE phases, for simplicity, the mixedlayer depth in Eq. (3) is specified as the climatological seasonal mean value $(\sim 40 \mathrm{~m})$ in JJA (see Du et al. 2005). Table 3 lists positive and negative IODE events used for our composite study. There are total of 12 negative and 11 positive IODE cases.

Figure 3 shows the composite SSTA and surface wind stress anomaly fields for positive and negative IODE events. An east-west dipole of SSTA is clearly seen in the Indian Ocean, with warm (cold) SSTA off Sumatra accompanied by cyclonic (anticyclonic) wind anomalies or northwesterly (southeasterly) wind anomalies along the coast of Sumatra. Whereas both the composites have a similar horizontal pattern with an opposite mirror image, the amplitude of SST and wind anomalies in the negative IODE is much stronger than that in the positive IODE.

The composite evolution of the mixing layer temperature (MLT) and its tendency $\left(\partial T^{\prime} / \partial t\right)$ are illustrated in Fig. 4. Note that initial SST perturbations in May in both positive and negative events have similar amplitude, but they diverge quickly after August, and at the mature phase (October) the amplitude of MLT in the negative IODE composite is almost doubled $\left(0.6^{\circ} \mathrm{C}\right)$ compared with that in the positive IODE composite $\left(0.3^{\circ} \mathrm{C}\right)$. The MLT asymmetry in the mature phase is obviously attributed to the asymmetry of MLT tendency during the developing stage. From the time evolution of the MLT tendency term, one may clearly see that the maximum difference of the temperature tendency between the positive and negative composites appears in JJAS. Therefore, it is crucial to examine the dynamic and thermodynamic processes that give rise to the asymmetric MLT tendency during the developing phase.

The estimate of MLT tendency by the sum of 3D ocean temperature advection and the sum of surface heat flux terms is shown in Fig. 5. Comparing to the actual temperature tendency, the estimated heat budget captures the major evolution feature such as a maximum MLT tendency in August and much stronger cooling than warming tendencies. However, because surface heat fluxes used for the budget analysis come from a different data source (i.e., from the NCEP-NCAR reanalysis, as SODA used a restoring term in the SST equation so that it does not provide the surface flux information), an exact balance cannot be achieved. While the asymmetry of MLT tendency between the positive and negative IODE events is well presented, a caution is needed as the analysis may overestimate the ocean advection and surface heat flux effects in the negative IODE phase.

Table 4 lists the relative contribution of the ocean advection and the net surface heat flux to $\partial T^{\prime} / \partial t$ in June-September (JJAS). Note that both the ocean temperature advection and the surface heat fluxes contribute significantly to the negative skewness in the east pole. While the amplitude of the surface heat flux contribution is about 3 times stronger in the negative phase than in the positive phase, the difference in the ocean dynamic effect is even greater ( 8 times). The fact that the amplitude of total MLT tendency in the negative phase is much greater than its counterpart in the positive phase explains why the cold SSTA grow much faster than the warm episodes in the east pole. In the following, we investigate the specific processes that give rise to the asymmetric MLT tendency.

\section{a. Effect of nonlinear temperature advection}

To understand the role of the ocean dynamics in causing the MLT tendency asymmetry, we decompose $3 \mathrm{D}$ ocean temperature advection into the zonal, meridional, and vertical temperature advection components. Also we further decompose them into linear and nonlinear advection terms by separating the climatological annual cycle and interannual anomaly fields. The sum of both the linear and nonlinear advection terms in contributing to the asymmetric MLT tendency is shown in Fig. 6. The amplitudes of both linear and nonlinear advections are greater in the negative IODE phase than in the positive IODE phase. Note that while the linear advection terms contribute to the growth of both the positive and negative IODE, the nonlinear terms (which have the same magnitude as the linear terms) tend to cool the MLT in both the warm and cold episodes. This reveals that the nonlinear advection may play an important role in causing the negative skewness in the east pole. A further analysis indicates that both horizontal and vertical nonlinear advection terms contribute significantly to the negative skewness. 

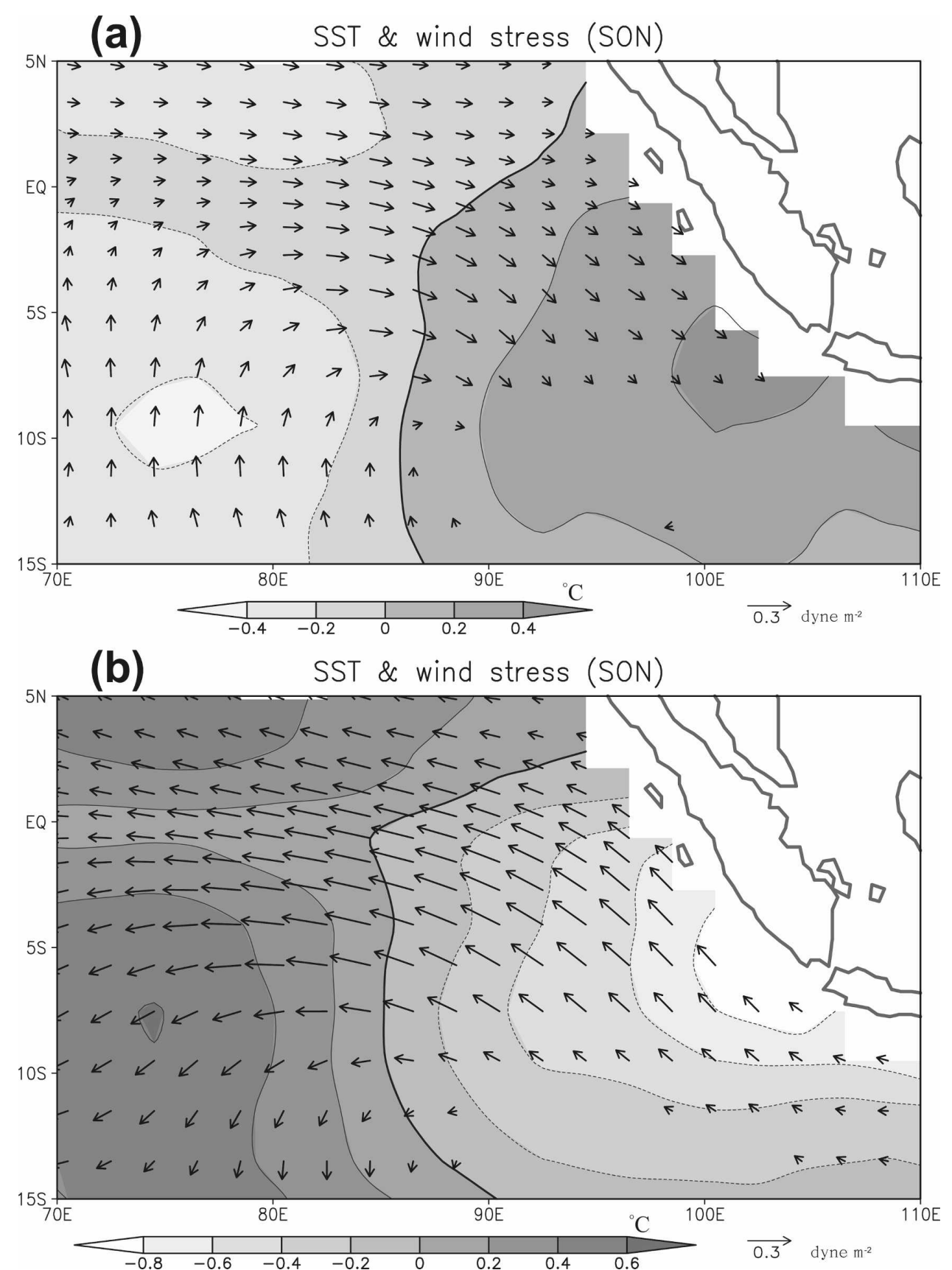

FIG. 3. Composite SST and surface wind stress anomalies during SON for (a) positive and (b) negative IODE events. The unit vector of the wind stress anomaly is 0.1 dyne $\mathrm{m}^{-2}$.

The spatial patterns (Fig. 7) of the nonlinear advection terms show that the vertical advection has a strong cooling tendency at the equator, but it is much weaker near the coast of Sumatra. This implies that the SODA product may underestimate the effect of coastal upwelling. In general, the box-averaged vertical advection has comparable magnitude to the horizontal advection. The analysis above points out that the nonlinear ad- vection is crucial in causing the IODE asymmetry. Figure 8 is a schematic diagram illustrating physically how the nonlinear advection terms may contribute to this asymmetry. Assume that initial positive and negative SSTA have the same amplitude. In response to a positive SST anomaly, anomalous westerlies along the equator and cyclonic wind curl over the off equator are generated. The anomalous westerlies induce eastward 


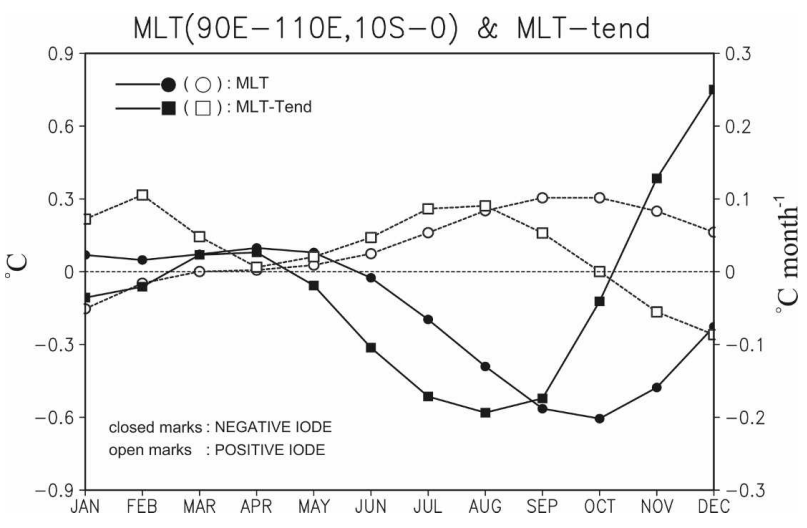

FIG. 4. Composite mixed-layer temperature (circles) and mixedlayer temperature tendency (squares). Open (closed) marks denote the positive (negative) IODE events.

Ekman transport. Also, the off-equatorial cyclonic curl induces cyclonic oceanic Rossby waves, which lead eastward geostrophic current. Therefore, there are strong eastward current in positive IODE case. This eastward current advects the anomalous cold temperature from west to east and leads to a cold advection (i.e., $-u^{\prime} \partial T^{\prime} / \partial x<0$ ). For the negative IODE events, westward anomalous currents and negative anomalous zonal temperature gradients (i.e., $u^{\prime}<0, \partial T^{\prime} / \partial x<0$ ) also lead to a cold advection $\left(-u^{\prime} \partial T^{\prime} / \partial x<0\right)$. [The importance of the nonlinear process in the IOD development was previously discussed in Murtugudde et al. (2000) and Halkides et al. (2006).] Therefore, the nonlinear zonal temperature advection tends to have a negative MLT tendency and cool the ocean surface for both positive and negative IODE events, and thus contributes to the amplitude asymmetry.

A similar argument may be applied for the nonlinear

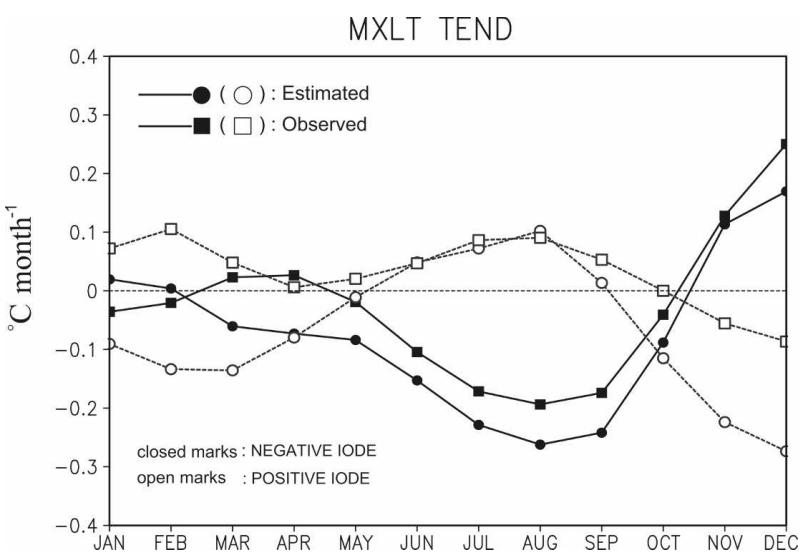

FIG. 5. Same as in Fig. 4 but for the mixed-layer temperature tendency (squares) and the sum of the ocean advection and surface heat flux terms (circles).
TABLE 4. Contributions of ocean advection and surface heat flux terms to the mixed-layer temperature tendency during JJAS.

\begin{tabular}{lcc}
\hline \multicolumn{1}{c}{ Catalog } & Ocean advection & Heat flux \\
\hline Negative IODE & -0.16 & -0.11 \\
Positive IODE & +0.02 & +0.04 \\
\hline
\end{tabular}

vertical advection. The left panels of Fig. 9 illustrate the depth-longitude profiles of ocean temperature averaged over $0^{\circ}-10^{\circ} \mathrm{S}$. Note that the maximum amplitude of the ocean temperature anomaly appears at the subsurface layer, and the anomalous vertical velocity at the base of the mixed layer is downward (upward) for the positive (negative) IODE event. As the climatological vertical velocity off the coast of Sumatra is upwelling during the IOD developing phase (JJAS), an anomalous downwelling (upwelling) during a positive (negative) IODE event tends to reduce (enhance) the mean upwelling and thus warm (cool) SSTA through the linear term, $-w^{\prime} \partial \bar{T} / \partial z$. Meanwhile, another linear advection term, $-\bar{W} \partial T^{\prime} / \partial z$, also tends to warm (cool) SSTA because of the negative (positive) anomalous vertical temperature gradient during the positive (negative) IODE events. As a result, both the linear vertical advection terms, $-\bar{W} \partial T^{\prime} / \partial z$ and $-w^{\prime} \partial \bar{T} / \partial z$, tend to enhance MLT anomalies for both the positive and negative IODE events.

However, the effect of the nonlinear vertical advection is different. For a negative IODE event, an anomalous upwelling $\left(w^{\prime}>0\right)$ acting to a positive temperature gradient anomaly leads to a cold advection in the mixing layer (i.e., $-w^{\prime} \partial T^{\prime} / \partial z<0$ ). For a positive IODE event, an anomalous downwelling $\left(w^{\prime}<0\right)$ acting to a negative temperature gradient anomaly also leads to a cold advection in the mixing layer (i.e., $-w^{\prime} \partial T^{\prime} / \partial z<0$ ). As a result, the nonlinear vertical temperature advection, along with the nonlinear horizontal advection, plays an important role in enhancing (reducing) the negative (positive) IODE events and causing the negative skewness in the east pole.

\section{b. Effects of the wind-evaporation-SST feedback and the cloud-radiation-SST feedback}

Next, we focus on examining the possible role of the surface heat fluxes in causing the IODE asymmetry. As shown in Table 4, the asymmetry of the surface heat flux anomaly is another significant contributor to the negative skewness, in addition to the nonlinear ocean advection process. Previous studies showed that the anomalous heat flux is mainly contributed by latent heat flux and net downward shortwave radiation anomalies, and the former plays an important role in 


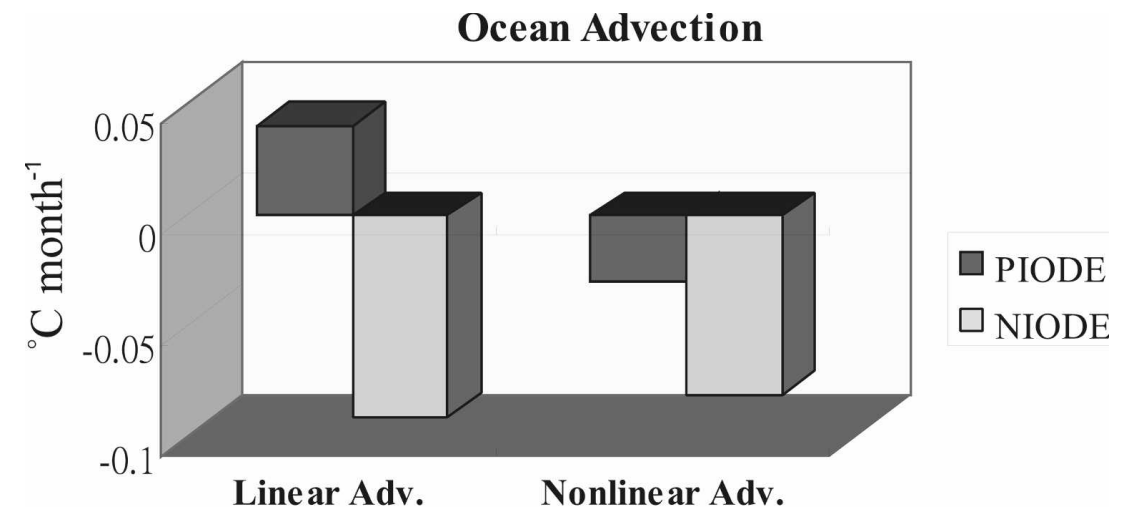

FIG. 6. Relative contribution of linear advection and nonlinear advection terms in contribution to mixed-layer temperature tendency in JJAS.

enhancing the SSTA during the IODE developing phase, whereas the latter tends to damp the SSTA and has a maximum impact in the mature phase $(\mathrm{Li}$ et al. 2002; Zhong et al. 2005).

Figure 10 shows the horizontal patterns of the composite $Q_{\mathrm{LH}}, Q_{\mathrm{SR}}$, and SST anomaly fields. To reflect their respective peak phase, the composite latent heat flux anomaly is taken during JJA while the net surface solar radiation anomaly is taken during SON. As expected, the latent heat flux anomaly tends to increase the cold SSTA, while the solar radiation anomaly tends to damp the SSTA. As discussed in Li et al. (2003), the effect of the evaporation-wind-SST feedback is season dependent, and depends on the change of seasonal (a)

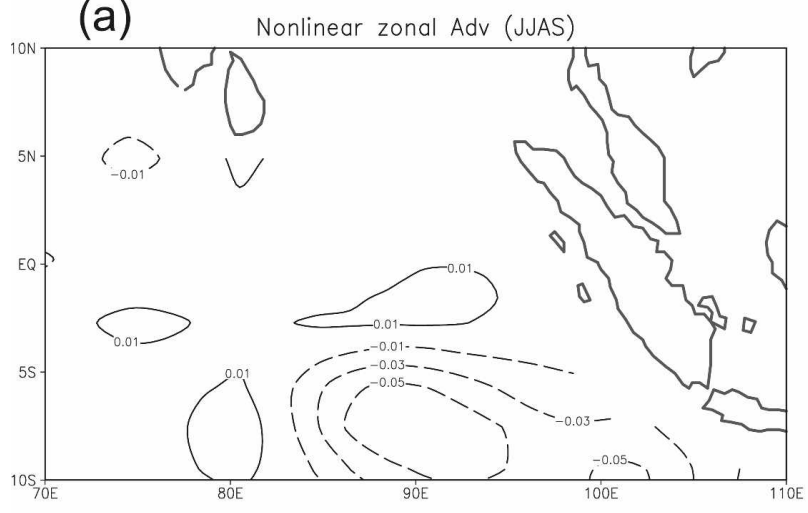

(c)

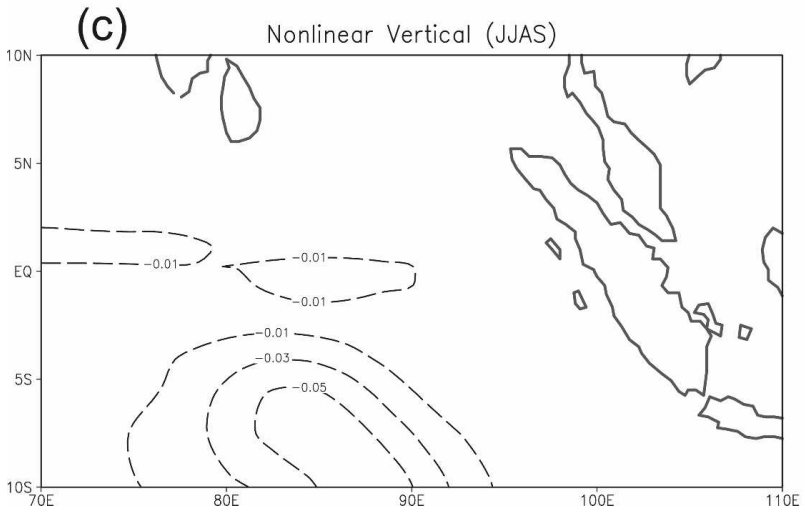

(b)

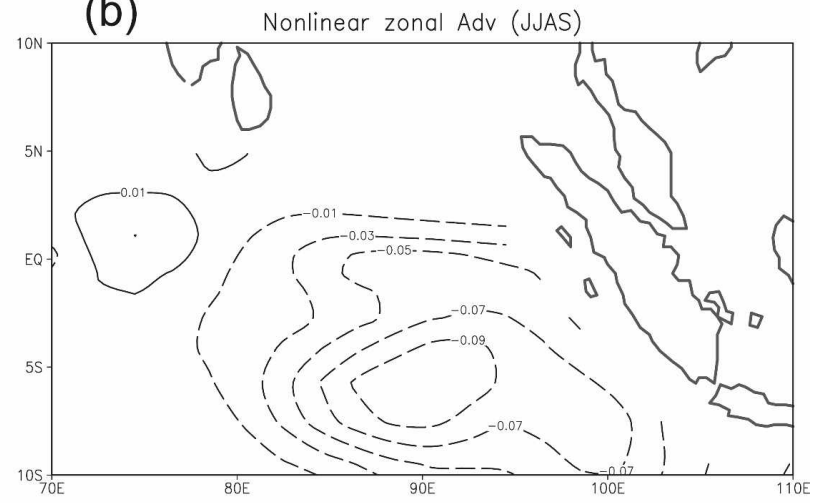

(d)

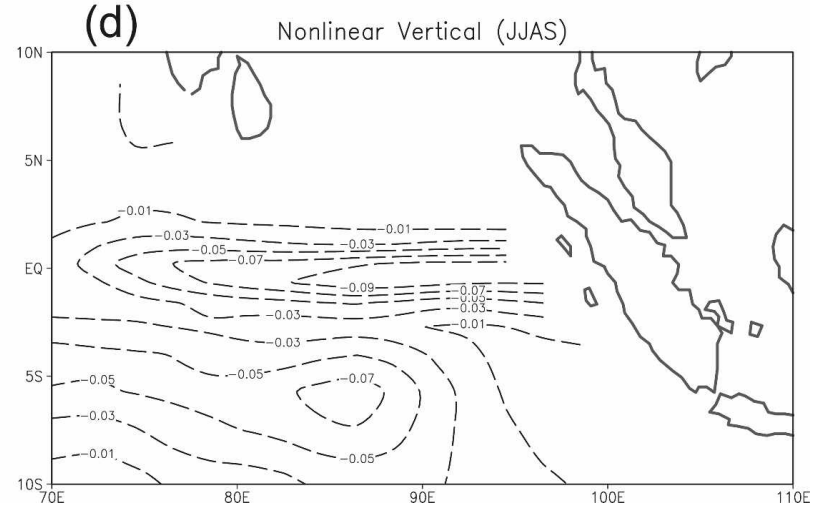

FIG. 7. (top) Nonlinear zonal and (bottom) vertical temperature advection patterns for the (left) positive and (right) negative IODE composites in JJAS. Contour interval is $0.01^{\circ} \mathrm{C}$ month ${ }^{-1}$ and starts from $\pm 0.01^{\circ} \mathrm{C} \mathrm{month}{ }^{-1}$. 
(a)

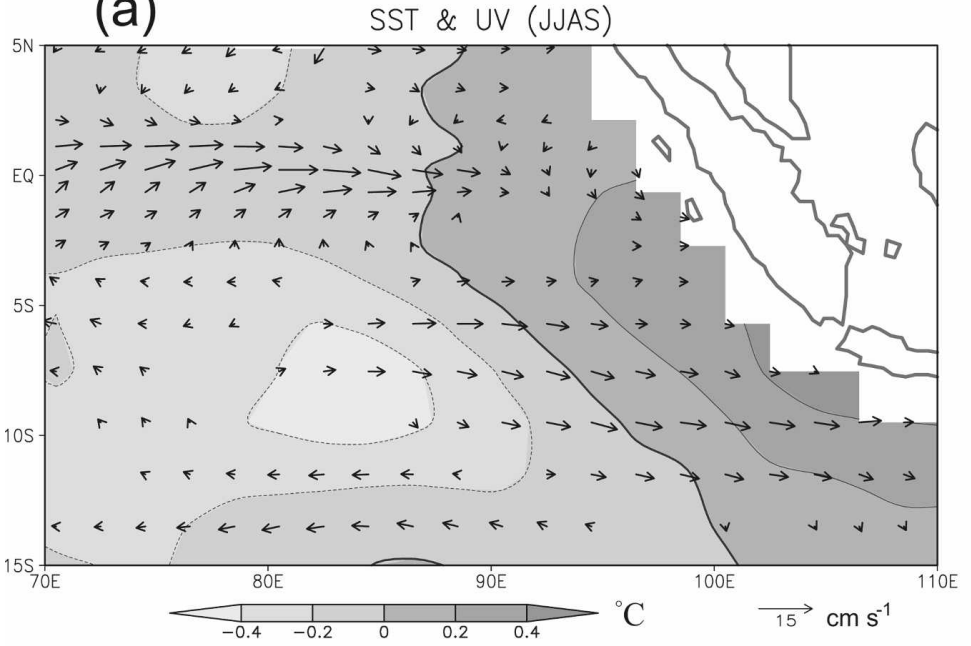

(b)

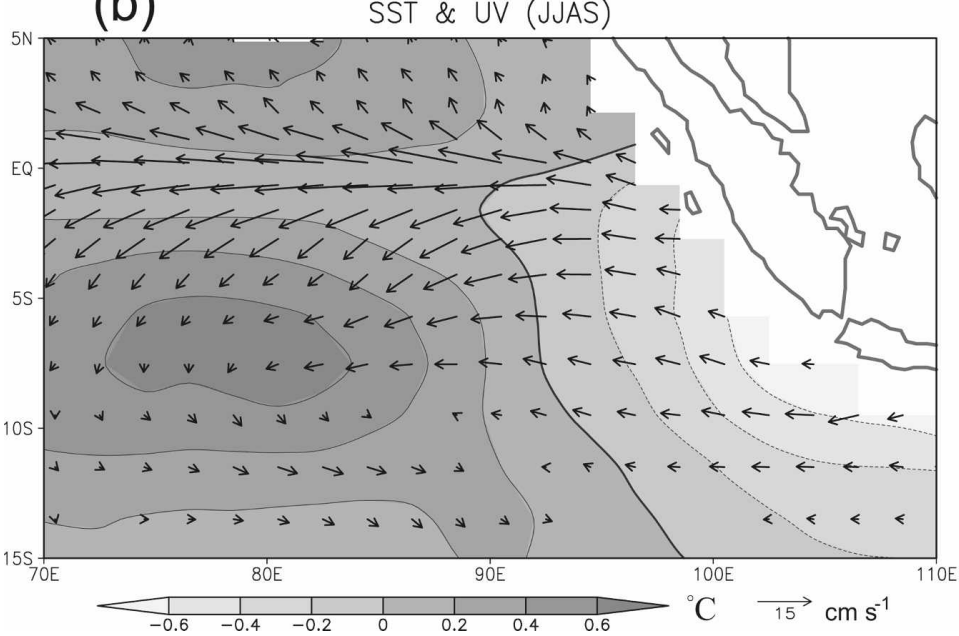

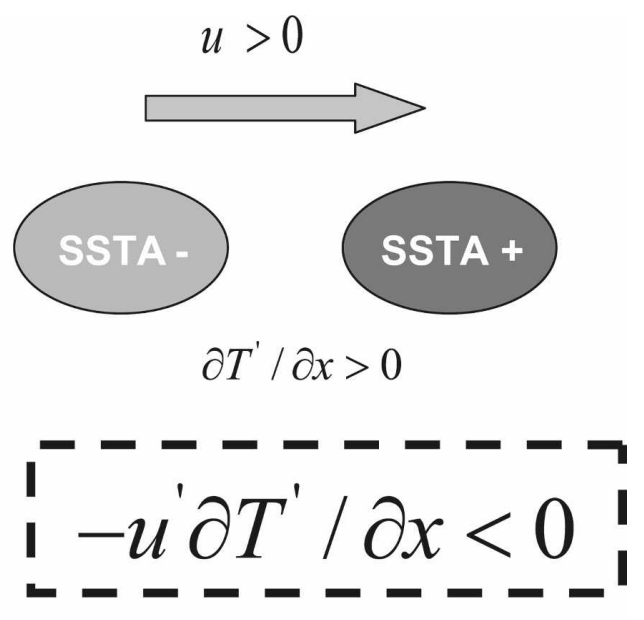

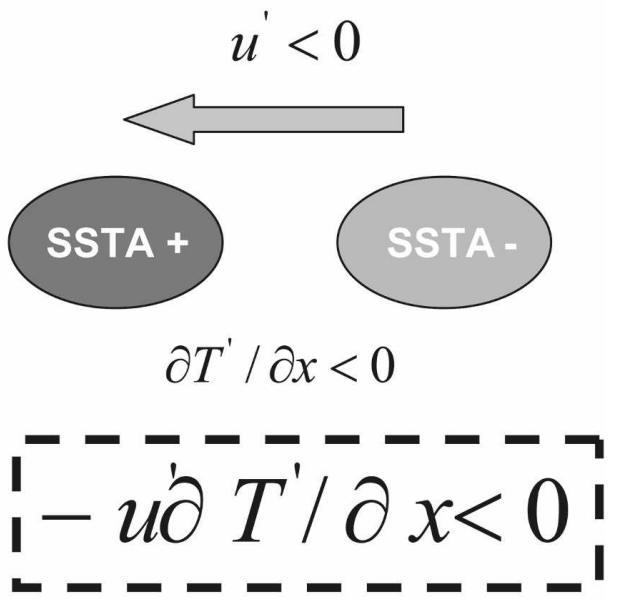

FIG. 8. (left) Mixed-layer temperature and horizontal ocean current $(z=7.5 \mathrm{~m})$ anomalies in JJAS for the positive and negative IODE composites. The unit vector of the ocean current is $15 \mathrm{~cm} \mathrm{~s}^{-1}$. (right) Schematic diagram of the nonlinear zonal advection.

mean winds. It exhibits a positive feedback in boreal summer but a negative feedback in boreal winter. The cloud-radiation-SST feedback, on the other hand, always acts as a negative feedback process (Ramanathan and Collins 1991; Li et al. 2000).

Table 5 lists the relative contributions of $Q_{\mathrm{LH}}$ and $Q_{\mathrm{SR}}$ in both the positive and negative IODE episodes. Note that the latent heat flux anomaly is twice as large in the negative episode as that in the positive episode in JJAS. This indicates that the wind-evaporation-SST feedback contributes to the IODE asymmetry. However, this evaporation-wind feedback does not create an asymmetry between the positive and negative episode, and it only magnifies the amplitude asymmetry created by other physical processes such as the aforementioned nonlinear ocean dynamics. This is because stronger cold SSTA may cause stronger anomalous wind response, and the anomalous wind may further interact with the mean wind and lead to enhanced evaporation that cools the ocean further. If the initial positive and negative SSTA have the same magnitude, it is expected that the magnitude of the anomalous wind response will be the same and the resulting surface latent heat fluxes remain symmetric. As a result, the amplitude of the positive and negative SSTA is kept same. Therefore, the evaporation-wind-SST feedback becomes efficient to magnify the asymmetry only after a significant asymmetry between the positive and negative episodes has been generated by other feedback processes.

Next, we pay special attention to the cloud-radiation-SST feedback. As the maximum amplitude of the 
(a) $T^{\prime} \& W^{\prime}($ JJAS $)$

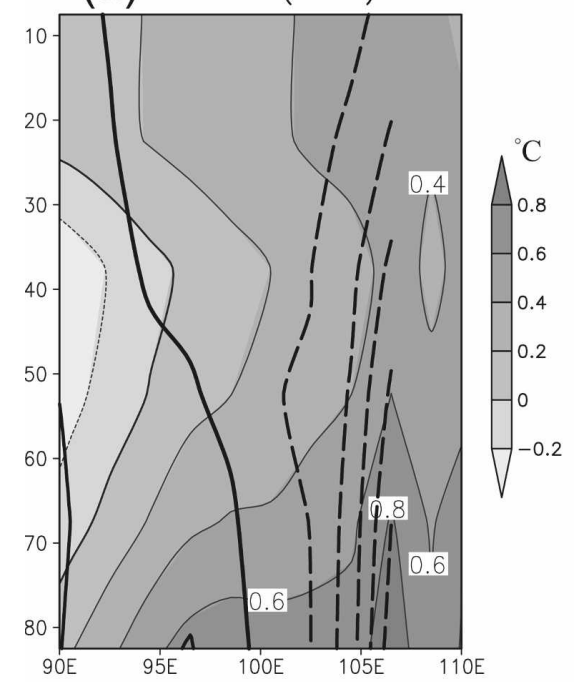

(b) $T^{\prime} \& W^{\prime}$ (JJAS)

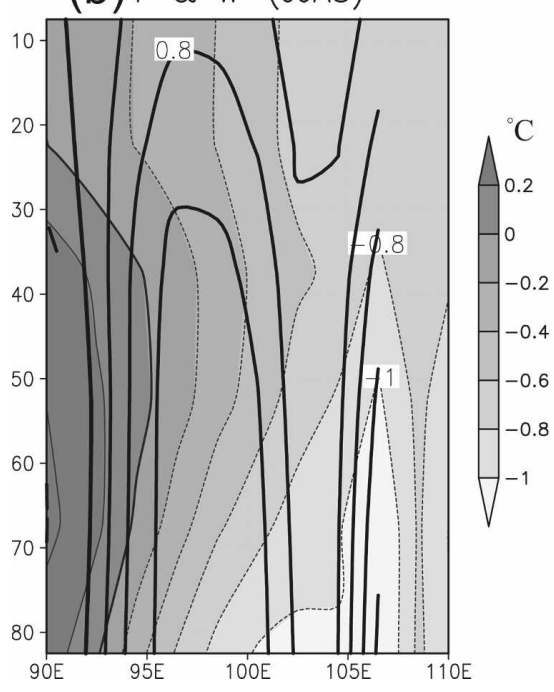

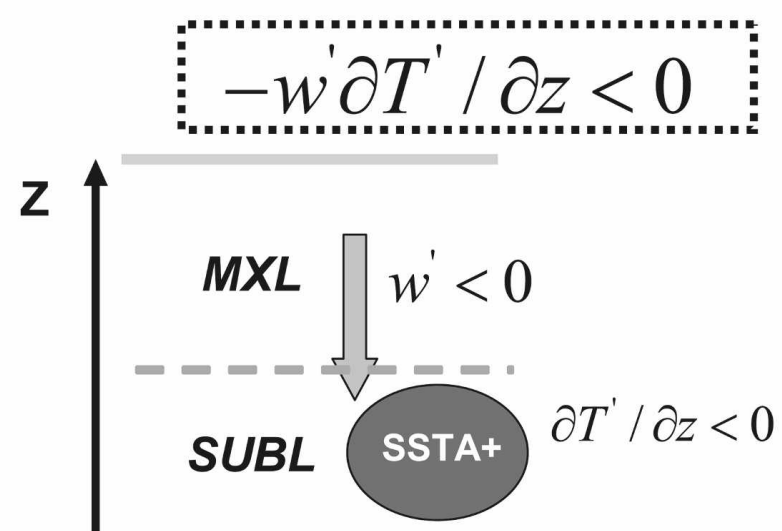

$\mathbf{Z}$
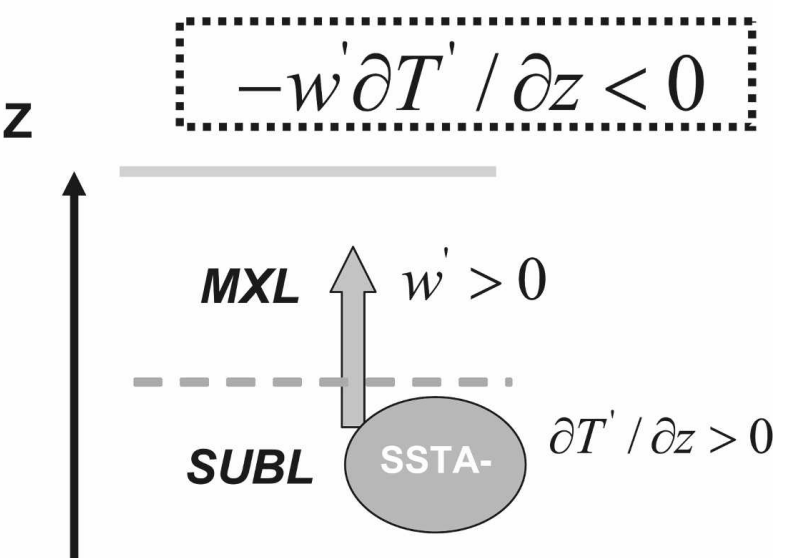

FIG. 9. (left) Depth-longitude section of the anomalous ocean temperature (shading) and vertical velocity (contour) fields for (a) positive and (b) negative IODE composites. The vertical velocity has been multiplied $10^{4}$. The contour intervals are $0.2 \mathrm{~cm} \mathrm{~s}^{-1}$. (right) Schematic diagram of the effect of the nonlinear vertical temperature advection.

SSTA and its relevant cloud radiation forcing appears in SON, we focus on the relationship between $Q_{\mathrm{SR}}$ and SSTA in this season. Table 5 shows that during the mature phase when the ratio of the SSTA amplitude between the negative and positive IODE is $2: 1$, the ratio of magnitude of the cloud shortwave radiation forcing is only 1.4:1. This indicates that the thermodynamic damping associated with the cloud-radiationSST feedback is inefficient in the negative IODE episodes. In other words, given the same SSTA amplitude, the cloud-radiation forcing is strongly asymmetric between the positive and negative episodes. This asym- metric effect of the cloud-radiation-SST feedback is another fundamental cause of the negative skewness in IODE.

To understand how the asymmetric effect of the cloud-radiation-SST feedback results, we show the scatter diagram for the precipitation-SST and $Q_{\mathrm{SR}}-\mathrm{SST}$ relationships as shown in Fig. 11. In general, the SSTA are positively correlated with the precipitation anomalies $(r=0.76)$ while negatively correlated with the surface shortwave radiation anomalies $(r=-0.72)$. However, the relationships are not simply linear. When the SSTA amplitude is relatively small, the relationships 
(a) SST \& LHT JJA

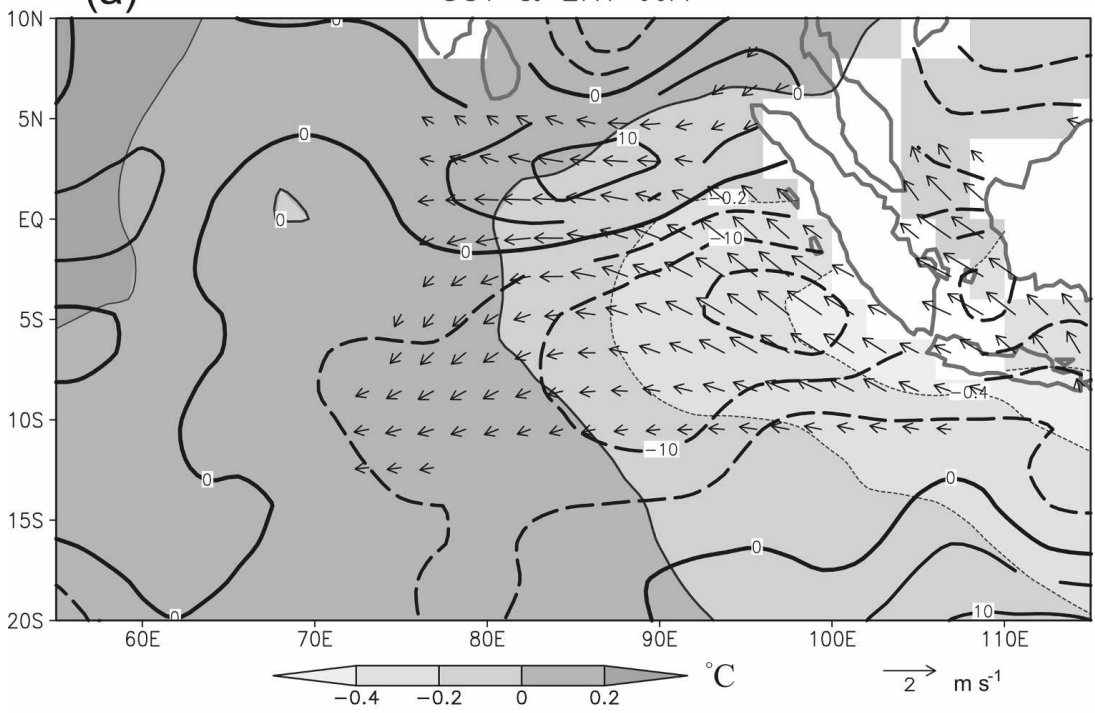

(b)

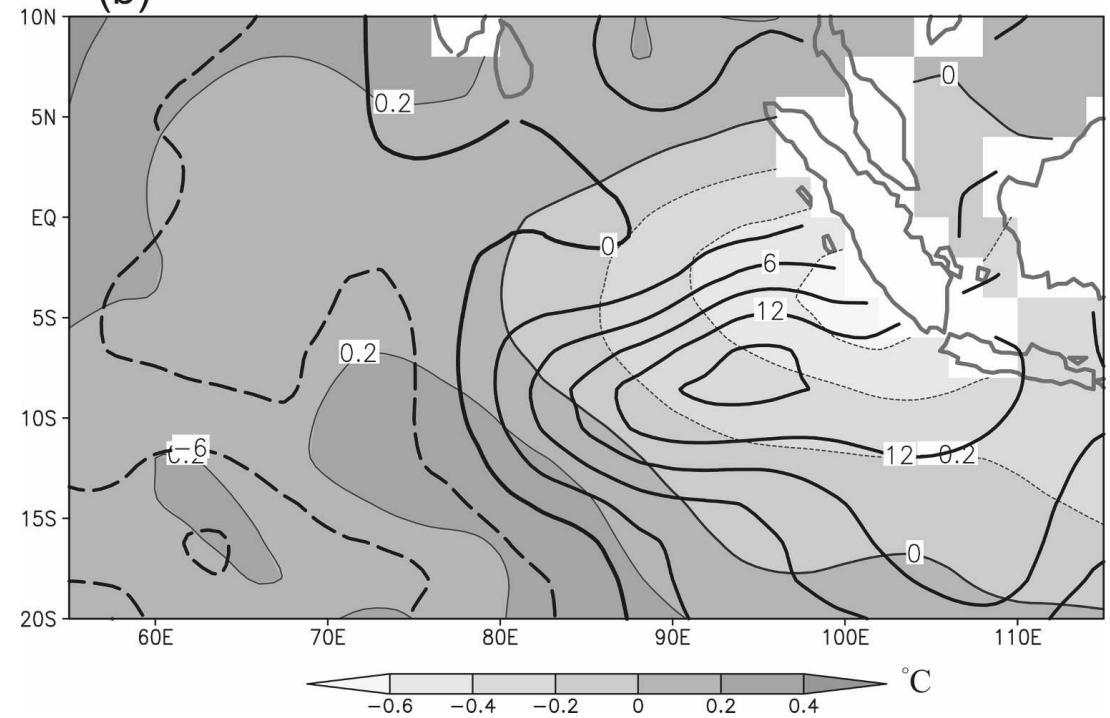

FIG. 10. (a) Composite SST (shaded), surface latent heat flux (contour), and 850-hPa wind anomalies in JJA and (b) composite SST (shading) and net downward solar radiation (contour) anomalies in SON during the negative IODE events. The unit vector of the wind anomalies is $1 \mathrm{~m} \mathrm{~s}^{-1}$. The contour intervals are $5 \mathrm{~W} \mathrm{~m}^{-2}$ for the latent heat flux and $3 \mathrm{~W}$ $\mathrm{m}^{-2}$ for the solar radiation. A positive heat flux indicates heating the ocean.

TABLE 5. Contributions of the latent heat flux and net downward solar radiation to the mixed-layer temperature tendency.

\begin{tabular}{lcc}
\hline \multicolumn{1}{c}{ Catalog } & Latent flux (JJAS) & Solar radiation (SON) \\
\hline Negative IODE & -0.22 & 0.17 \\
Positive IODE & 0.11 & -0.12 \\
Ratio & 2.0 & 1.4 \\
\hline
\end{tabular}

are in general linear, indicating that precipitation anomalies increase and shortwave radiation anomalies decrease with increased SSTA. However, after the cold SSTA reach a certain magnitude (say, $-2 \sigma$ ), even with continuous increase of the cold SSTA, the precipitation anomaly stops decreasing and is saturated to a critical value. Similarly, the shortwave radiation anomaly is 

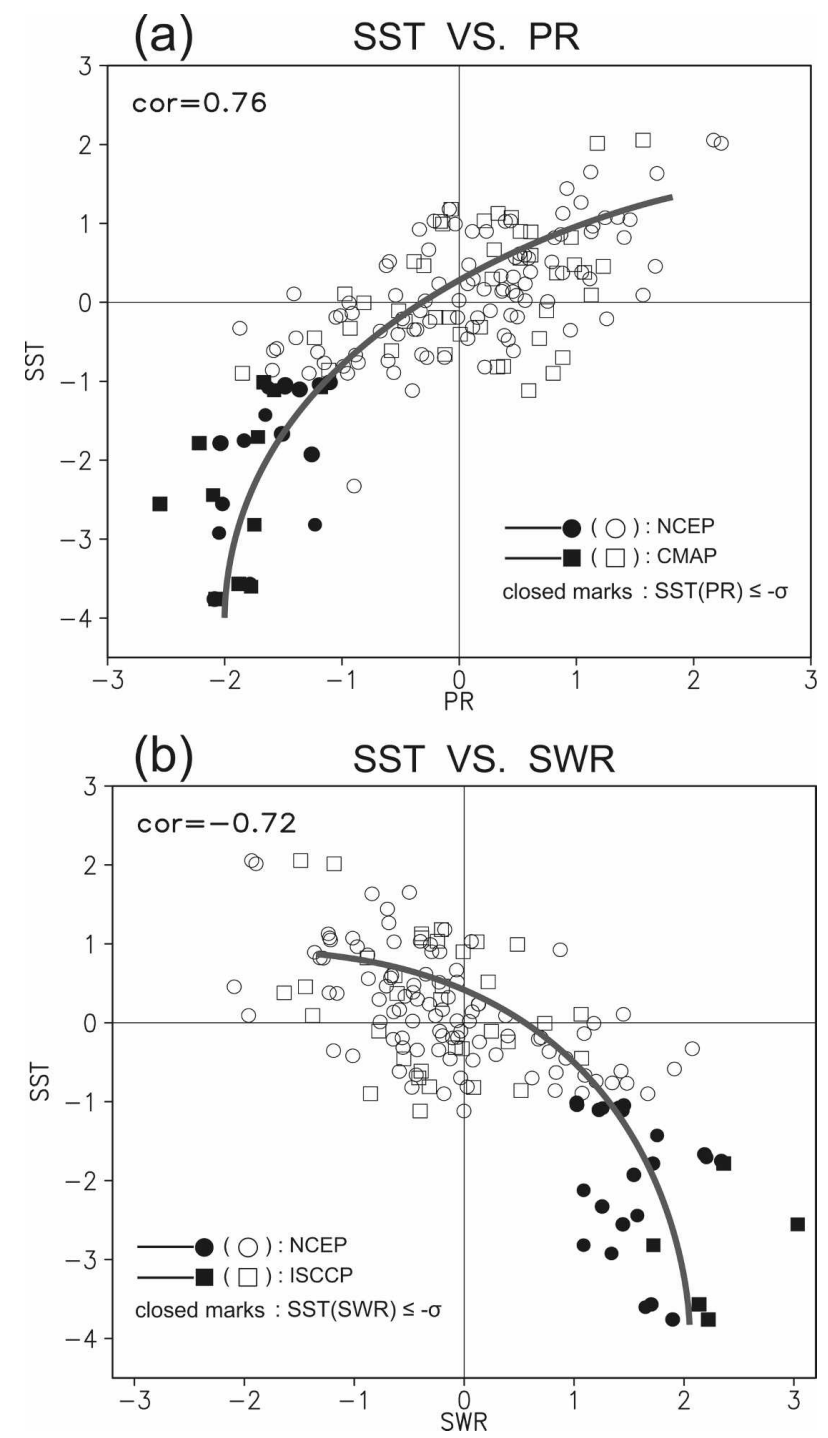

FIG. 11. Scatter diagrams for the (a) SST-precipitation and (b) SST-surface shortwave radiation relationships. Monthly anomaly data in September and October are plotted in the scatter diagrams. All fields have been normalized with respect to their standard deviations. The blue dots indicate that the normalized SST and precipitation/shortwave radiation exceed one standard deviation. In addition to the NCEP-NCAR reanalysis data, the CMAP precipitation (1979-2001) and the ISCCP radiation (1984-2001) are included for extreme negative events (closed marks).

also saturated. This means that the thermodynamic damping due to the cloud radiation forcing does not work any more after the cold SSTA reach a critical amplitude. Therefore, the cold SSTA may grow faster due to lack of thermal damping.

Why does the cloud-radiation-SST feedback exhibit such an asymmetric feature? Figure 12 illustrates schematically how this mechanism works. The eastern equatorial Indian Ocean is a region where climatological mean convection is permanent throughout the year in the view of seasonal mean time scale. A positive SST anomaly in situ would lead to enhanced convection and thus enhanced negative cloud shortwave radiation forcing, which may damp the positive SSTA. A modest cold SST anomaly, on the other hand, may reduce the mean convection and reduce the cloud amount. As a result, a negative cloud-SST feedback may still exist. When the amplitude of the cold SSTA reaches to a critical value, the cold SSTA may completely suppress the mean convection $\left(\sim 3.5 \mathrm{~mm}\right.$ month $\left.^{-1}\right)$ and lead to cloud free conditions. With the continuous growth of the cold SSTA below this critical value, no additional negative convective heating anomaly can be generated, and as a result, the anomalous precipitation and cloud amount remain constant even though the SSTA may further drop.

To make sure that the asymmetric cloud-radiationSST feedback is a robust feature, we also calculate the anomalous precipitation, shortwave radiation, and SST relationships using the International Satellite Cloud Climatology Project (ISCCP) radiation (Zhang et al. 2004) and Climate Prediction Center (CPC) Merged Analysis of Precipitation (CMAP) precipitation (Xie and Arkin 1996) products. The results show that the asymmetric relationships are essentially the same.

\section{Summary and discussion}

In this study we investigate the amplitude asymmetry of SSTA between the positive and negative IOD events by diagnosing the SODA and NCAR/NCEP reanalysis data. The strength of the asymmetry is measured by the concept of skewness. A mixed-layer heat budget analysis is conducted to understand specific dynamic and thermodynamic mechanisms that lead to the asymmetry. The main results are summarized as below:

1) A significant negative skewness for SSTA appears in the southeast Indian Ocean off Sumatra during the mature phase of IOD, while the near-zero skewness appears in the western Indian Ocean. In addition to the negative skewness in the SSTA, the surface wind stress and thermocline depth anomalies also exhibit a significant negative skewness. The IOD amplitude asymmetry is primarily caused by the asymmetry in the east pole.

2) The negative skewness of the SSTA in the east pole is season dependent, and it only appears in SON, the IOD mature phase. There is no clear evidence showing that the negative skewness results from the asymmetry of remote El Niño-La Niña forcing in northern summer.

3) The mixed-layer heat budget analysis indicates that 


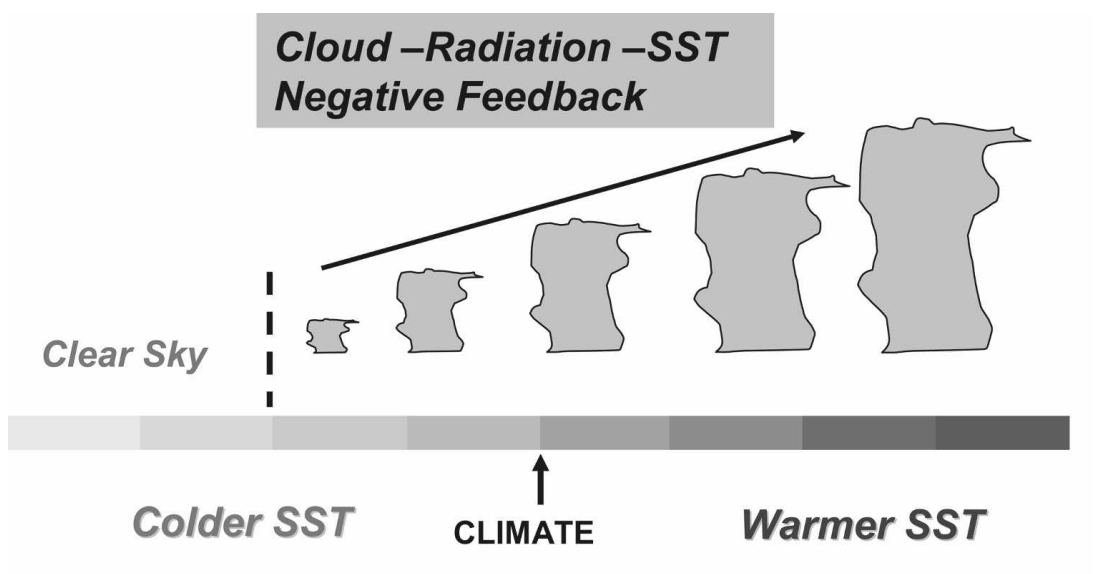

NON-LINEAR LINEAR

FIG. 12. Schematic diagram illustrating the nonlinear feature of the cloud-radiationSST feedback.

the negative skewness in the east pole is mainly induced by (i) anomalous nonlinear horizontal and vertical ocean temperature advection and (ii) the asymmetry of cloud-radiation-SSTA feedbacks between the positive and negative IOD events. The wind-evaporation-SST feedback plays a role in enhancing the amplitude asymmetry.

The fact that the negative skewness appears in both the ocean and atmospheric variables such as SST, wind stress, and thermocline depth fields suggests that both ocean dynamics and air-sea coupling processes might be crucial for the IOD amplitude asymmetry. Because the maximum heating/cooling rate for MLT tendency appears in the IOD developing stage, we focus our diagnostics in JJAS, even though the maximum negative skewness appears in SON. The mixed-layer heat budget analysis shows that the time change rate of MLT is quite different between the positive and negative events in JJAS, even though the initial SSTA perturbation has similar amplitude in May. Both the ocean dynamics (i.e., 3D temperature advection) and surface heat flux processes contribute to this asymmetric development.

Further diagnosis indicates that the nonlinear ocean advection plays a crucial role. While the linear ocean advection terms contribute to the growth of both the positive and negative SSTA, the nonlinear advection terms have an asymmetric effect-they tend to cool the ocean in both the warm and cold episodes, thus enhancing the cold events but weakening the warm events. Both the nonlinear horizontal and vertical advections contribute to this asymmetric MLT tendency.

In addition to the nonlinear ocean effect, the cloud-
radiation-SST feedback is another important mechanism for generating amplitude asymmetry. This is because the negative cloud radiation forcing linearly increases with increased SSTA for the positive IODE but does not behave so for the negative IODE. Instead, the thermal damping associated with the cloud-radiationSST feedback significantly weakens when the cold SSTA reach a critical amplitude (see the schematic diagram of Fig. 12 for detailed discussion of this mechanism). Finally, the surface evaporation-SST-wind feedback may efficiently amplify the SSTA asymmetry as a stronger (weaker) cold (warm) SST anomaly in JJAS may lead to a greater (weaker) along-coast wind and thus a larger (weaker) surface evaporation anomaly.

In an accompanying paper (Part II), we diagnose high-resolution air-sea coupled simulations from a long-term (420 yr) run of SINTEX-F1, with the same diagnostic method. The residual term in the mixedlayer heat budget is much smaller. The same nonlinear mechanisms (i.e., nonlinear ocean advection and cloudradiation forcing) contribute to the IOD asymmetry. This confirms the robustness of the role of the aforementioned dynamic and thermodynamic air-sea feedback processes in causing the asymmetry.

The role of the nonlinear advection on the IODE asymmetry is quite different from the El Niño-La Niña asymmetry as the eastern equatorial Pacific has a positive rather than negative skewness. The exact cause of this difference is currently under investigation. As anomalous rainfall and SST centers have a significant zonal phase difference in ENSO events (Li et al. 2003), the effect of the negative cloud-radiation-SST feedback might be weaker, compared to the IOD events. 
The IOD may modify the ENSO amplitude/evolution through induced west and east Walker circulations over the equatorial Indian and Pacific Oceans (e.g., Li et al. 2003, 2006; Kug and Kang 2006; Kug et al. 2006a,b). Given the negative skewness of IODE, it is expected that this remote IOD forcing might be asymmetric. Thus, the stronger El Niño (weaker La Niña) amplitude may result from stronger westerly (weaker easterly) wind response in the western Pacific in association with the stronger positive phase (weaker negative phase) IOD forcing. This deserves further detailed analyses.

Acknowledgments. We thank both reviewers for their valuable comments. This study was completed when $\mathrm{CCH}$ visited IPRC, University of Hawaii at Manoa. $\mathrm{CCH}$ was supported by NSC 95-211-M133-001-AP4 and NSC-96-2745-M-002. TL was supported by NSFC Grants $40628006 / 40675054$ and ONR Grants N000140710145/N000140210532 and by the International Pacific Research Center, which is partially sponsored by the Japan Agency for Marine-Earth Science and Technology (JAMSTEC).

\section{REFERENCES}

An, S.-I., and F.-F. Jin, 2004: Nonlinearity and asymmetry of ENSO. J. Climate, 17, 2399-2412.

Baquero-Bernal, A., M. Latif, and S. Legutke, 2002: On dipolelike variability of sea surface temperature in the tropical Indian Ocean. J. Climate, 15, 1358-1368.

Behera, S. K., J. J. Luo, S. Masson, S. A. Rao, H. Sakuma, and T. Yamagata, 2006: A CGCM study on the interaction between IOD and ENSO. J. Climate, 19, 1688-1705.

Cai, W., H. H. Hendon, and G. Meyers, 2005: Indian Ocean dipolelike variability in the CSIRO Mark 3 coupled model. $J$. Climate, 18, 1449-1468.

Carton, J., G. Chepurin, X. Cao, and B. Giese, 2000: A simple ocean data assimilation analysis of the global upper ocean 1950-95. Part I: Methodology. J. Phys. Oceanogr., 30, 294309.

Dommenget, D., and M. Latif, 2002: A cautionary note on the interpretation of EOFs. J. Climate, 15, 216-225.

Du, Y., T. Qu, G. Meyers, Y. Masumoto, and H. Sasaki, 2005: Seasonal heat budget in mixed layer of the southeastern tropical Indian Ocean in a high-resolution general circulation model. J. Geophys. Res., 110, C04012, doi:10.1029/ 2004JC002845.

Halkides, D. J., W. Han, and P. J. Webster, 2006: Effects of the seasonal cycle on the development and termination of the Indian Ocean zonal dipole mode. J. Geophys. Res., 111, C12017, doi:10.1029/2005JC003247.

Hong, C.-C., M.-M. Lu, and M. Kanamitsu, 2008a: Temporal and spatial characteristics of positive and negative Indian Ocean dipole with and without ENSO. J. Geophys. Res., 113, D0817, doi:10.1029/2007JD009151.

_- T. Li, and J.-J. Luo, 2008b: Asymmetry of the Indian Ocean dipole. Part II: Model diagnosis. J. Climate, 21, 4849-4858.

Huang, B., and J. L. Kinter III, 2001: The interannual variability in the tropical Indian Ocean and its relation to El Niño/
Southern Oscillation. COLA Tech. Rep. 94, Center for Ocean-Land-Atmosphere Studies, Calverton, MD, 48 pp.

Kalnay, E., and Coauthors, 1996: The NCEP/NCAR 40-Year Reanalysis Project. Bull. Amer. Meteor. Soc., 77, 437-471.

Krishnamurthy, V., and B. P. Kirtman, 2003: Variability of Indian Ocean: Relation to monsoon and ENSO. Quart. J. Roy. Meteor. Soc., 129, 1623-1646.

Kug, J.-S., and I.-S. Kang, 2006: Interactive feedback between the Indian Ocean and ENSO. J. Climate, 19, 1784-1801.

_ , S.-I. An, F.-F. Jin, and I.-S. Kang, 2005: Preconditions for El Nino and La Nina onsets and their relation to the Indian Ocean. Geophys. Res. Lett., 32, L05706, doi:10.1029/ 2004 GL021674.

— B. P. Kirtman, and I.-S. Kang, 2006a: Interactive feedback between ENSO and the Indian Ocean in an interactive coupled model. J. Climate, 19, 6371-6381.

_ 2006b: Role of ENSO-Indian coupling on ENSO variability in a coupled GSM. Geophys. Res. Lett., 33, L09710, doi:10.1029/2005GL024916.

Lau, N.-C., and M. J. Nath, 2004: Coupled GCM simulation of atmosphere-ocean variability associated with zonally asymmetric SST changes in the tropical Indian Ocean. J. Climate, 17, 245-265.

Li, T., T.-F. Hogan, and C.-P. Chang, 2000: Dynamic and thermodynamic regulation of ocean warming. J. Atmos. Sci., 57, 3353-3365.

—, Y.-S. Zhang, C.-P. Chang, E. Lu, and D. Wang, 2002: Relative role of dynamic and thermodynamic processes in the development of the Indian Ocean dipole: An OGCM diagnosis. Geophys. Res. Lett., 29, 2110, doi:10.1029/2002GL015789.

- B. Wang, C.-P. Chang, and Y. Zang, 2003: A theory for the Indian Ocean dipole-zonal mode. J. Atmos. Sci., 60, 2119 2135.

_- P. Liu, X. Fu, B. Wang, and G. Meehl, 2006: Spatiotemporal structures and mechanisms of the tropospheric biennial oscillation in the Indo-Pacific warm ocean regions. J. Climate, 19, 3070-3087.

Luo, J.-J., S. Masson, S. Behera, P. Delecluse, S. Gualdi, A. Navarra, and T. Yamagata, 2003: South Pacific origin of the decadal ENSO-like variation as simulated by a coupled GCM. Geophys. Res. Lett., 30, 2250, doi:10.1029/ 2003 GL018649.

Murtugudde, R., J. P. McCreary, and A. J. Busalacchi, 2000: Oceanic processes associated with anomalous events in the Indian Ocean with relevance to 1997-1998. J. Geophys. Res., 105, 3295-3306.

Ramanathan, V., and W. Collins, 1991: Thermodynamic regulation of ocean warming by cirrus clouds deduced from observations of the $1987 \mathrm{El}$ Niño. Nature, 351, 27-32.

Saji, N. H., and T. Yamagata, 2003: Structure of SST and surface wind variability during Indian Ocean dipole mode events: COADS observations. J. Climate, 16, 2735-2751.

- B. N. Goswami, P. N. Vinayachandran, and T. Yamagata, 1999: A dipole mode in the tropical Indian Ocean. Nature, 401, 360-363.

Shinoda, T., M. A. Alexander, and H. H. Hendon, 2004: Remote response of the Indian Ocean to interannual SST variations in the tropical Pacific. J. Climate, 17, 362-372.

Smith, T. M., R. W. Reynolds, R. E. Livezey, and D. C. Stokes, 1996: Reconstruction of historical sea surface temperature using empirical orthogonal functions. J. Climate, 9, 1403 1420. 
Tozuka, T., J.-J. Luo, S. Masson, S. K. Behera, and T. Yamagata, 2005: Annual ENSO simulated in a coupled oceanatmosphere model. Dyn. Atmos. Oceans, 39, 41-60.

Trenberth, K. E., 1997: The definition of El Niño. Bull. Amer. Meteor. Soc., 78, 2771-2777.

Webster, P. J., A. M. Moore, J. P. Loschnigg, and R. R. Leben, 1999: Coupled ocean-atmosphere dynamics in the Indian Ocean during 1997-1998. Nature, 401, 356-360.

White, H. G., 1980: Skewness, kurtosis and extreme values of Northern Hemisphere geopotential heights. Mon. Wea. Rev., 108, 1446-1455.

Xie, P., and P. K. Arkin, 1996: Analyses of global monthly precipitation using gauge observations, satellite estimates, and numerical predictions. J. Climate, 9, 840-858

Xie, S.-P., H. Annamalai, F. A. Schott, and J. P. McCreary Jr.,
2002: Structure and mechanisms of South Indian Ocean climate variability. J. Climate, 15, 864-878.

Yu, J.-Y., and K. M. Lau, 2004: Contrasting Indian Ocean SST variability with and without ENSO influence: A coupled atmosphere-ocean study. Meteor. Atmos. Phys., 90, 179-191, doi:10.1007/s00703-004-0094-7.

Zhang, Y.-C., W. B. Rossow, A. A. Lacis, V. Oinas, and M. I. Mishchenko, 2004: Calculation of radiative fluxes from the surface to top based on ISCCP and other global data sets: Refinements of the radiative transfer model and the input data. J. Geophys. Res., 109, D19105, doi:10.1029/ 2003JD004457.

Zhong, A., H. H. Hendon, and O. Alves, 2005: Indian Ocean variability and its association with ENSO in a global coupled model. J. Climate, 18, 3634-3649. 